\title{
A noção de competência na gestão de pessoas: reflexões acerca do setor público
}

Francielle Molon da Silva e Simone Portella Teixeira de Mello

\section{Introdução}

Os acontecimentos que marcaram os últimos anos no cenário mundial revelam um diagnóstico cambiante. Fatos políticos e econômicos elucidam mudanças recentes que incidem no desempenho de mercados e sociedades e, consequentemente, das organizações, tanto públicas quanto privadas. Percebese, também, novos estilos de vida, desvelando um movimento social que também se reflete nas organizações, na medida em que se passa a dar mais ênfase ao desenvolvimento e à educação em organizações, muito além do tradicional treinamento. É o que salientam Borges-Andrade et al (2006) ao abordarem o espectro da aprendizagem mediando teoria e prática.

E é nesse mosaico de mutações que emerge a gestão por competências como estratégia de eficácia organizacional, articulando o desenvolvimento humano e social dos trabalhadores com as necessidades da gestão organizacional. Esta abordagem parece ser fruto da modernidade organizacional, que articula processos 
individuais e coletivos como meio de contribuir para o desenvolvimento e melhor desempenho frente ao novo cenário cambiante de reestruturação produtiva.

Ruas, Antonello e Boff (2005) propõem que a construção da noção de competências passa pela crescente instabilidade econômica, baixa previsibilidade do mercado e das relações da empresa com seus clientes e pela intensificação de estratégias de customização. Esses fatores levam a conceber novas formas de organizar o trabalho, se passa de uma disposição do trabalho mais estável e previsível para outra diferenciada e fluida, em que a previsão tende a ser mais focada no que se deve obter do trabalho e no seu resultado, do que no processo em si, naquilo que deve ser feito.

Esse é o contexto no qual se instala e se propaga a noção de competências, porém, não significa que exista consenso do que se entende como competência. A própria noção de competência tem uma compreensão difusa e extensiva em relação ao seu entendimento e aplicação. Então, acredita-se ser oportuno resgatar as concepções que balizam a gestão por competências, enquanto estratégia para melhoria do desempenho organizacional, destacando possibilidades de aplicação da noção por competências associada à alteração do papel de gestão de pessoas para o setor público.

\section{Abordagem por competências considerando a estratégia}

Ao tratar sobre o tema, é oportuno iniciar a relação competências e estratégia a partir das contribuições de McClelland (1973) e Boyatzis (1982), pois eles são considerados os precursores no debate acerca de competências. Eles partem da escola norte-americana e propõem as competências como inputs, ou seja, as qualidades requeridas ao exercício de um cargo, relacionadas unicamente ao conjunto de conhecimentos, habilidades e atitudes (CHA). Essa noção, hoje, torna-se inviável pelo contexto incerto e de mudanças dinâmicas em que estão as organizações (Becker e Lacombe, 2005).

Todavia, o contexto organizacional dinâmico, com preocupações sobre adequações ao ambiente, faz com que outros temas sejam associados à discussão sobre competências, como é o caso da estratégia. Os estudos sobre essa abordagem levam a perceber que o ambiente é uma variável considerável na formulação de estratégias. Forças ambientais constituem aspectos relevantes para o desenvolvimento da eficácia organizacional. A natureza político-legal, econômica, tecnológica, social ou global de uma organização são exemplos dessas forças (PorTer, 1986). Mas, aliado à análise do ambiente, é necessária uma trajetória de objetivos definidos, tais como: a implementação de estratégias, o controle de resultados e os diversos ajustes quando necessários, sintonizando as estratégias funcionais às organizacionais, $\mathrm{o}$ que pressupõe desafios na gestão de pessoas em se tratando de desenvolvimento de competências tanto individuais quanto coletivas.

Para Mertens (1996), um clássico sobre o tema, o conceito de competência compreende conhecimento e habilidades constatadas. Existe diferença entre habilidades e conhecimentos mostrados no posto de trabalho e os resultados exigidos de uma pessoa que ocupa esse posto. A qualificação, por sua vez, se projeta no desempenho do posto, em saber cumprir as normas de conhecimento e habilidade, 
enquanto que a competência se projeta no resultado que deve cumprir a pessoa ligada ao posto, tais como conhecimentos e habilidades que assegurem um produto desejado. Enquanto a qualificação se circunscreve ao posto, a competência se centra na pessoa, que pode chegar a ocupar um ou mais postos de trabalho, o que subjaz no conceito de multifunção.

A proposta dos anos 1960 se centrava em validar a qualificação dos trabalhadores, confrontando-a com o desempenho requerido num dado posto de trabalho com tarefas predeterminadas, prescritas, em que o desempenho era formulado mediante análise ocupacional. O desempenho se limitava à realização da tarefa, ou seja, ao saber fazer. Porém, a competência não parte de uma tarefa preestabelecida, mas sim é redefinida constantemente em função dos resultados esperados, em função das vantagens obtidas diante de estratégias bemsucedidas.

Então, pode-se dizer que competência implica ação, o que vai além do saber e do fazer, pois pressupõe uma atitude, responsabilidade, iniciativa entre tantos substantivos (ZARIFIAN, 2001).

Mais recentemente o estudo sobre competências tem contribuído para o construto de estratégias organizacionais bem-sucedidas, tendo como pano de fundo o desenvolvimento de lideranças capazes de mobilizar saberes e transpor conhecimentos às equipes visando o desempenho organizacional eficaz e harmônico, destacando-se aspectos como autonomia, responsabilidade, fomentando valores como a iniciativa e a polivalência (Deluiz, 2004).

Estudos recentes apresentam a competência em pelo menos duas grandes perspectivas, estando cada uma delas atrelada a um eixo conceitual (DiAs et al., 2008). O primeiro refere-se à dimensão estratégica das organizações, provocando um debate importante para o desenvolvimento da competitividade. Nessa dimensão, encontram-se as contribuições dos desdobramentos da Visão Baseada em Recursos (Penrose, 1959; Wernerfelt, 1984; Rumelt, 1984; Barney, 2001), da noção de core competence (PRAHALAD e Hamel, 2000) e de novas formulações que

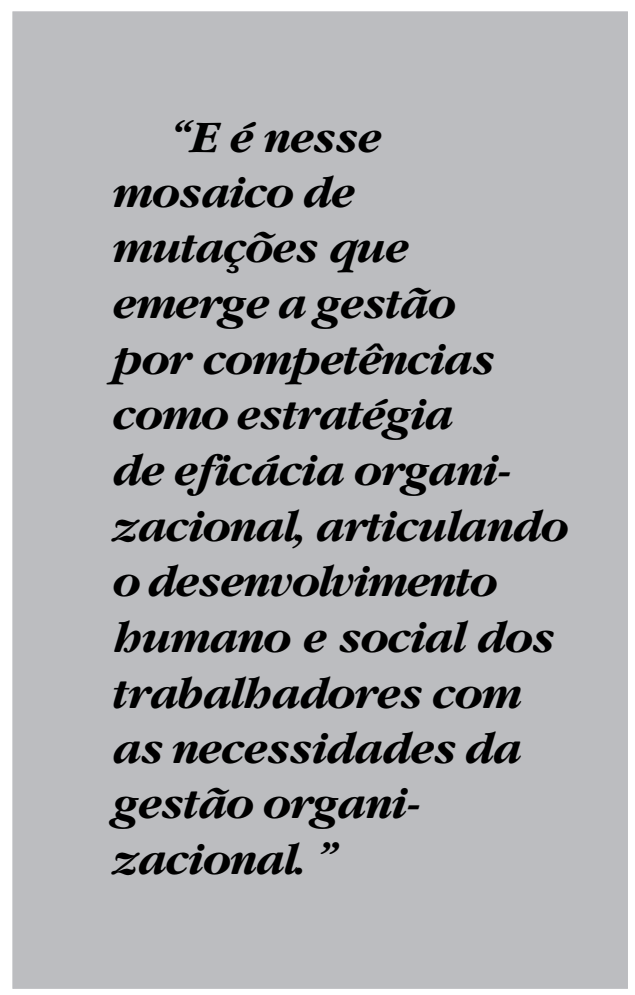

valorizam o dinamismo da relação entre o ambiente externo e competências e recursos internos, como elemento a ser considerado na formulação estratégica (TEECE, Pisano e Shuen, 1997).

O segundo eixo conceitual, que debate as competências, é associado a práticas próprias de gestão de pessoas, como seleção, desenvolvimento, avaliação e 
remuneração (Dutra, 2001). Essa é a versão mais conhecida e difundida das competências individuais. Dentro dessa perspectiva, podemos encontrar contribuições mais conhecidas de McClelland (1973), Boyatzis (1982), Le Boterf (1995), Zarifian (2001) e Dutra (2004).

Ao longo dos anos, teorias e abordagens administrativas têm mostrado que o sucesso organizacional é resultante de diversas variáveis, desde a eficácia na gestão de pessoas, no gerenciamento dos processos com foco nos resultados, assim como na prospecção de alternativas como meio de prever decisões diante do inusitado.

Os estudos sobre competências têm sua maior parte calcada sob o aspecto do indivíduo, do que sob a ótica da organização (Fisher, Fleury e Urban 2008). Por meio de pesquisas realizadas no Programa de Estudos em Gestão de Pessoas, os autores identificaram que a maior parte das organizações de grande porte busca programar um modelo de competências visualizando esse conceito como conjunto de conhecimentos, habilidades e atitudes dos indivíduos inseridos em seus contextos.

Dutra (2008) aponta que, embora teóricos e pessoas compreendam a competência como conjunto de conhecimentos, habilidades e atitudes (CHA), esse enfoque é pouco instrumental, pois o fato de algumas pessoas possuírem o CHA não é garantia de que haverá agregação de valor à organização. E essa agregação de valor está relacionada a algo que a pessoa entrega de maneira efetiva à organização e que lá permanece independentemente de essa pessoa estar ou não lá. Então, a agregação de valor não é somente atingir metas, mas melhorar processos e introduzir inovações.

Dessa maneira, observa-se que uma das formas de se atribuir significado à dimensão da competência individual ultrapassa a compreensão do CHA pois, atualmente, na linha teórica e prática, essa noção pode ser encontrada de maneira ampliada, embora ainda seja possível encontrá-la sob a forma reduzida, considerando as primeiras construções sobre essa noção, que remetem à qualificação.

A partir dos anos de 1990, sob influência europeia, mais precisamente da Escola Francesa, o foco da competência recai sobre o momento da ação, sobre a continuidade e mobilização das capacidades, relacionada, assim, a "fazer a coisa certa, no momento certo". Le Boterf e Zarifian colaboram a respeito dessa temática. Para Le Boterf (1994), a competência relacionava-se à agregação de valor e entrega a determinado contexto independente do cargo, ou seja, à parte da própria pessoa. Já Zarifian (2001) propõe a noção de competência associada à iniciativa, responsabilidade e inteligência prática da pessoa em situações cotidianas, apoiada em conhecimentos adquiridos e transformados. Ele também acrescenta a noção de "evento" ao associar a instabilidade na qual os profissionais estão inseridos.

Essa noção contemporânea é vista como output, com o foco no contexto, onde se destacam os trabalhos de Dutra (2008), associando as competências à noção de entrega, voltada a resultados e agregação de valor. Assim, as pessoas possuem um conjunto de competências que podem ou não estar sendo aproveitadas pela organização, sendo definidas como "capacidade de agregar valor ao patrimônio de conhecimentos da organização" (Dutra, 2008). Nesse sentido, não seria recomendado pensar as competências individuais de forma genérica, mas sim atreladas às competências essenciais da organização (DUTRA, 2008). 
Já no início do século XXI, a competência é pensada, pelo menos no discurso, sem necessariamente tratar de forma sistemática, na perspectiva da sua contribuição econômica e social. É a fase da difusão e afirmação do conceito associado à "entrega" (Dutra, Fleury e RuAs, 2008). Nessa perspectiva, Fleury e Fleury (2006) contribuem com a ideia de que a competência pode ser entendida como fonte de valor para o indivíduo e fonte de valor para a organização, ou seja, "um saber agir responsável e reconhecido, que implica mobilizar, integrar, transferir conhecimentos, habilidades que agreguem valor econômico à organização e valor social ao indivíduo" (FLEURY e FLEURY, 2006). Mas com a ressalva de que essa colocação é vista pelo menos em discurso, mas não necessariamente ocorre dessa forma na prática. Se forem analisadas as práticas utilizadas nas organizações, pode-se notar que há uma desarticulação entre a agregação de valor para a organização e para o individuo. Isso porque muitas das ferramentas de recursos humanos, ditas como competências, acabam focando no sujeito, na capacitação e carreira da pessoa, mas ainda como uma rotina da área de $\mathrm{RH}$, e não como algo articulado com a organização e sua estratégia, fazendo com que a 'tal' agregação de valor conjunta - indivíduoorganização - seja unilateral ou inexistente.

Os elementos como mobilização de recursos, relevância da comunicação, o papel da aprendizagem, comprometimento e responsabilidade, bem como a visão estratégica, demonstram a importância da questão individual de conhecimento e desenvolvimento para alcançar a dimensão organizacional. Para ocorrer um processo articulado entre pessoas e organização é necessário haver um processo de troca de competências, o que é apontado por Dutra (2008) quando expressa que:

A organização transfere seu patrimônio para as pessoas, enriquecendo-as e preparando-as para enfrentar novas situações profissionais e pessoais, na organização ou fora dela. As pessoas, ao desenvolverem sua capacidade individual, transferem para a organização o seu aprendizado, capacitando-a a enfrentar novos desafios (Dutra, 2008, p. 24).

Além disso, a competência pode ser definida, na perspectiva de Ropé e Tanguy (1997), como atributo que se refere à subjetividade da pessoa e está diretamente ligada à capacidade dela de mobilizar saberes e atitudes necessárias para, de forma autônoma, resolver problemas em dadas situações. Sendo assim, aspectos subjetivos passam a ter relevância e prioridade na organização e na gestão estratégica das organizações, enquanto que recrutamento, remuneração e promoção começam a ser realizados não mais por cargos, mas por competências, o que significa deslocamento do foco do posto de trabalho, da tarefa para o indivíduo, a pessoa (ZARIFIAN, 1998).

Zarifian, citado por Tartuce (2004), traz precisão ao conceito de competência. Numa perspectiva multidimensional o autor destaca que, de um lado, a competência se refere à capacidade para agir em situações específicas e imprevisíveis, decorrente da inteligência prática ancorada nos conhecimentos adquiridos que são transformados. De outro lado, designa o fato de ser reconhecida pelo julgamento de outros, tanto em termos sociais como financeiros. Em suma, a competência é 
concomitantemente tomada de responsabilidade de forma autônoma e reconhecimento social dessa tomada de responsabilidade. Mas, por privilegiar a subjetividade da competência, Zarifian não renega o lado social dessa, tendo em vista que a responsabilidade se inscreve também no coletivo do trabalho.

A contemporaneidade tem mostrado que entre as competências dos indivíduos e o desempenho estratégico das organizações, há de se considerar as competências coletivas, cujos processos de interação definem os produtos e serviços desejados. E é na base desse olhar que as organizações começam a perceber as competências coletivas como estratégicas, em que a gestão de RH pode contribuir na geração de vantagem concorrencial duradoura com base na teoria dos recursos. As competências coletivas, diferentemente das individuais, estão lá, mas muitas vezes não são visualizadas e, portanto, deixam de ser mobilizadas.

Os estudos de Pauvers e SchiebBienfait (RETour et al., 2011) revelam isso, ao destacarem as competências coletivas no limiar da estratégia, identificadas em um estudo de caso ao longo de seis anos, em que identificaram as seguintes competências estratégicas: o comprometimento e responsabilidade das equipes; a defesa da qualidade da oferta da organização; o domínio interno de toda a cadeia da concepção de um canteiro de obras, entendido aqui como construção e renovação das competências de cada atividade/função; assim como o domínio da cadeia de negociação dos serviços ofertados pela organização.

No mundo das organizações, a competência é considerada uma capacidade que só se evidencia numa situação de trabalho e que está sujeita a regras, procedimentos, instrumentos e consequências. Identifica resultados profissionais concretos que podem abranger funções diferentes, pois se refere a situações concretas de trabalho e não aos elementos estruturais de uma operação. Por isso não pode ser confundida com qualificação, pois a dinâmica, num sentido de mobilidade, é elemento central das competências.

Vale destacar que no Brasil o destaque à noção de competências se dá mais expressivamente nos anos 1980 e 1990, a partir de temas em pauta, como flexibilização das relações de trabalho e desemprego. Para Tartuce (2004), a qualificação do trabalho ganha destaque nos discursos do governo, empresários e sindicatos, como meio de aumentar a produtividade e, consequentemente, o desenvolvimento econômico do país. A competitividade que está em jogo requer pessoas com atributos diversos, capazes de gerenciar a diversidade, emergindo a noção de competências individuais e coletivas no contexto organizacional.

No que tange às estratégias empresariais e formação de competências, Fleury e Fleury (2004) acrescentam que as estratégias são estabelecidas por meio de diferentes competências organizacionais em três diferentes funções centrais: operações (produção e logística); desenvolvimento de produto (pesquisa, desenvolvimento e engenharia); e comercialização (vendas e marketing). E o desenvolvimento das demais competências nas funções organizacionais se dá para reforçar a competência essencial dessas funções centrais.

Para tanto, o processo de aprendizagem é essencial, pois faz a ligação entre competências e estratégias, para que ocorra um círculo virtuoso empresarial. Conforme os autores, o desenvolvimento de competências organizacionais em operações industriais 
compreende as seguintes áreas de desenvolvimento: competências técnicas; competências sobre a organização; competências de serviço; e competências sociais. Já no nível individual, envolve a sua relação com toda a empresa em uma perspectiva sistêmica, salientando as competências de negócios, competências técnico-profissionais e as competências sociais.

O que parece ser fundamental quando se opta por trabalhar com o desenvolvimento de competências individuais e coletivas é uma estrutura organizacional que realce a transparência. Aliado a isso, Fleury e Fleury (2004) destacam a transferência de conhecimento entre os empregados como fator decisivo no sucesso do processo. Szulanski, citado pelos autores, destaca que as ocasionais barreiras estão relacionadas a fatores ligados ao conhecimento, tais como: a inadequada capacidade de absorção por parte de quem recebe o conhecimento, que é uma função direta de seu estoque preexistente de conhecimento; a insegurança sobre quais são os fatores de produção envolvidos nas práticas, bem como seu processo de interação; as características peculiares, mal compreendidas por quem recebe a informação e a transforma em conhecimento, do contexto em que esse irá aplicar a determinada prática; e o relacionamento na maior parte das vezes tenso entre as pessoas envolvidas na transferência de conhecimento tácito - as chamadas manhas do trabalho -, o que infere ausência de empatia na maior parte das situações.

Além disso, quando se trata de competências diretivas das lideranças observa-se que essas estão associadas às competências empresariais (organizacionais e essenciais) e ao posicionamento eficaz da empresa no mercado, para obter a sua vantagem competitiva em relação à concorrência. $\mathrm{Ou}$ seja, as competências de liderança incidem diretamente na análise de ações estratégicas. Por isso, as contribuições individuais elencadas por Fleury e Fleury (2004) são elucidativas no cenário de negócios, e estão organizadas em três grandes blocos, que envolvem a relação do indivíduo com toda a empresa, em uma perspectiva sistêmica, que são:

- competências de negócios: relacionadas à compreensão dos negócios, seus

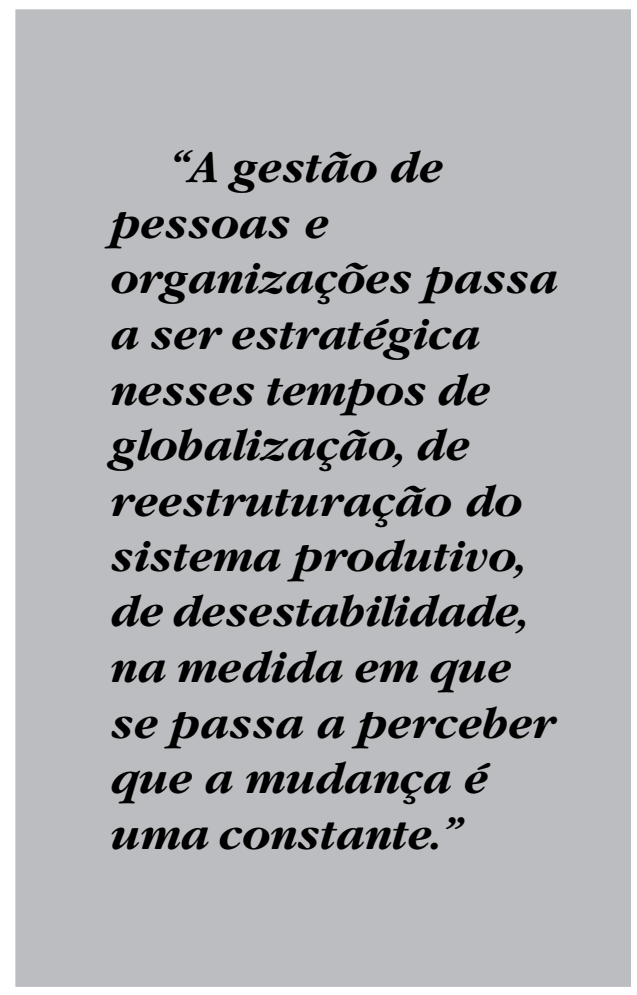

objetivos na relação com o mercado, clientes e competidores, ambiente político e social;

- competências técnico-profissionais: competências específicas para certa operação, ocupação ou atividade produção, comercialização, produtos, finanças;

- competências sociais: competências para interagir com as pessoas, comunicação, 
negociação, mobilização para mudanças, sensibilidade, cultura, trabalho em equipes etc.

Aliado a isso, a atitude, mencionada por Dutra (2004) por meio do conceito de "entrega", conforme mencionado anteriormente, é relevante no debate do processo de formação de competências dos indivíduos, pois indica um saber agir responsável e reconhecido à medida que é possível verificar os resultados produzidos de fato. Diz respeito às formas como os indivíduos utilizam suas habilidades e conhecimentos no dia a dia organizacional, o que eles realmente entregam à organização.

Percebe-se que as abordagens de gestão das organizações têm seus ciclos: ora valoriza as pessoas, ora os processos, ora o ambiente e outras categorias de análise. No entanto, a contemporaneidade tem forçado as organizações a retomarem o desenvolvimento humano de forma mais contundente. Os estudos sobre aprendizagem revelam o sucesso organizacional a partir das pessoas, das relações interpessoais bem-sucedidas, ressaltando aspectos como valores e propósitos compartilhados. Para Hock (1999), quando o propósito é compartilhado, quando se valoriza o coletivo, pode-se atingir a harmonia transformando as relações e, consequentemente, a organização.

Assim, a modernidade está a exigir um novo perfil de gestor estratégico de pessoas, para o qual a qualificação já não basta e parece estar sendo sobreposta pela competência. Um tipo de gestor, de tomador de decisão mais prospectivo, que se aproxima à taxonomia de tipos estratégicos de Miles e Snow (2003). A atividade de liderança não é mais simples, funcional, mas sim altamente complexa, de difícil e instigante exercício. $\mathrm{E}$ diante disso, a gestão estratégica de pessoas tem tratado da gestão por competências enquanto tema emergente, associando e coordenando competências individuais à construção de competências coletivas consideradas estratégicas para a organização (Mascarenhas, 2008).

Essa abordagem apresenta a competência como conjunto de saberes, motivações, capacidades e atitudes que se manifestam em desempenhos adequados e se alteram à medida que variam os contextos situacionais, mais frequentes no cenário mundial contemporâneo. Assim, diante de situações diferentes têm-se soluções diversas, mas que efetivamente resolvam um dado problema.

\section{A estratégia contemporânea da gestão de pessoas}

A gestão de pessoas e organizações passa a ser estratégica nesses tempos de globalização, de reestruturação do sistema produtivo, de desestabilidade, na medida em que se passa a perceber que a mudança é uma constante. A experiência em determinada tarefa ou função não leva as pessoas a serem competentes. Embora as competências tácitas sejam essenciais, há de se prestar mais atenção na variedade dos eventos enfrentados e no desempenho organizacional pretendido, nas relações que se pretende desenvolver para isso e as estratégias do negócio decorrentes disso.

Deluiz (2001) esclarece que as novas concepções gerenciais de competências decorrem da reestruturação produtiva e das mudanças no mundo do trabalho, tendo em vista a reorganização do próprio sistema capitalista como meio de manter sua hegemonia em resposta à crise estrutural do capital, o que atingiu não só a área de produção, mas os diversos espaços da sociabilidade. Para a autora, o alinhamento 
definitivo das políticas de recursos humanos às estratégias empresariais apontou novos elementos na gestão do trabalho e das pessoas, para dar conta da crescente competitividade dos mercados.

Para Bosquetti (2009), a abordagem estratégica da gestão de pessoas está criando novo campo de pesquisa, em decorrência de uma combinação dos argumentos da estratégia organizacional com os da gestão de pessoas. Nessa discussão, Lacombe (2006) chama atenção para a grande contribuição da abordagem de competências para a gestão de pessoas. Se pensada a partir da estratégia e dos recursos internos, funciona como um direcionador para a ação de práticas e políticas de planejamento e a ação da gestão de pessoas de maneira integrada.

Nesse contexto, partes desse todo complexo, que significa competência na gestão do trabalho, são: a valorização dos altos níveis de escolaridade nas normas contratuais; a valorização da mobilidade e do acompanhamento individualizado da carreira; novos critérios de avaliação que valorizam as competências relativas à mobilização no trabalho e seu compromisso com a organização; e a instigação à formação contínua. Sendo assim, a adoção do modelo de competências está associada ao uso, controle, formação e avaliação do desempenho da força de trabalho diante das exigências decorrentes da acumulação capitalista flexível destacada por Harvey (1996).

Além da flexibilidade, aparecem novos componentes na abordagem de gestão por competências, como a transferibilidade, a polivalência e a empregabilidade. No entendimento de Deluiz (2001), a transferibilidade tem sentido de mobilidade, de desempenhar uma e outra funções dentro da empresa, o que requer considerável polivalência e constante atualização dos saberes para atingir os níveis desejáveis de empregabilidade. As qualificações tácitas passam a assumir extrema relevância no modelo de competências. Não basta só o saber-fazer; o saber-ser e o saber em ação são aspectos da inteligência prática e do comportamento humano que independem de diplomas ou manuais.

Observa-se então que a polissemia do termo permeia as opiniões, pois se em alguns momentos ela encanta, em outros ela se mostra perversa (Mello, 2007). Ao analisar a polissemia do conceito de competências, a autora traz à tona os relatos de recém-graduados e do mercado de trabalho, retomando o debate da equivalência (ou não) entre o conceito de competência e o de qualificação, ou da questão de que o primeiro pode estar se sobrepondo ao segundo. Contudo, os resultados do estudo mostram que competências não podem ser reduzidas a uma racionalidade única. Elas podem ser objeto de compromisso e de reconhecimento individual. Mas quando esses acordos estão ausentes, seja na totalidade ou em partes, questiona-se a ausência de reconhecimento social que invalida a legitimidade do modelo.

\section{Discussão: a gestão por compe- tências em curso no setor público}

Apresentam-se a seguir experiências na gestão que se baseiam em competências no ambiente público, voltadas a questões estratégicas e de gestão de pessoas na área pública. Observa-se que há emergência da aplicação do tema voltado a questões estratégicas, mediadas por ações e práticas também estratégicas e articuladas de gestão de pessoas (GRIMAND, 2009).

Pires et al. (2005) apresentam iniciativas da Escola Nacional de Administração 
Pública (ENAP), que objetivam disponibilizar instrumentos para aumento da capacidade de governo na formulação e implementação de políticas públicas, tendo como suporte metodológico as contribuições da Canada School of Public Service (CSPS).

As notas destacam ações desenvolvidas por instituições do Poder Executivo, desde a definição de competências funcionais; criação de indicadores de desempenho para fins do desenho da estratégia organizacional; avaliações $360^{\circ}$, em que gerentes também são avaliados pelos seus subordinados; até a elaboração de planos de desenvolvimento individuais e institucionais, em que se percebe o desenvolvimento de competências organizacionais como metodologia de ação.

Marconi (2004), por sua vez, analisa a gestão de recursos humanos vigente no setor público e as políticas de RH que vêm sendo executadas. Seu estudo destaca as novas formas contratuais, como o desenho de cargos largos e o desenvolvimento de competências. Esses cargos têm uma concepção multifuncional, aglutinando atribuições de mesma natureza de trabalho. Um exemplo são os cargos largos como agentes administrativos, que reúnem atividades de suporte administrativo, como as exercidas por servidores públicos de nível médio nas áreas de compras, almoxarifado e contabilidade. Nesse caso, a mobilidade funcional aparece como característica marcante no desenvolvimento de competências, tendo em vista as atribuições amplas dentro da mesma função, tanto no âmbito individual quanto no organizacional.

Souza (2004), ao estudar a gestão por competências no segmento federal, descreve experiências sobre o ingresso no serviço público. Recentemente a Agência
Nacional de Energia Elétrica (Aneel) inovou, inserindo em concurso público o item de competências requeridas para determinados cargos. A investida, embora revele a subjetividade ainda presente no âmbito das competências, o que é passível de recursos em concursos públicos, mostra a iniciativa da agência em demonstrar desde o edital a política institucional para captar profissionais que, se aprovados, no decorrer de suas carreiras, serão aferidos por competências requeridas, tais como: visão sistêmica, comprometimento, aprendizagem contínua, flexibilidade, liderança e criatividade.

Essa autora também menciona o fato de as funções comissionadas técnicas, caracterizadas pela complexidade e responsabilidade, exigirem um profissional com conhecimentos, habilidades e atitudes para ocupar a função e com reconhecida qualificação, capacidade e experiência. Outra situação retrata o planejamento organizacional de necessidades de capacitação ou a forma inicial de sistematizar o modelo de gestão por competências para o contexto da administração pública, que consiste no planejamento de ações integradas e efetivas de desenvolvimento, a partir da identificação dos gaps de competência e da negociação do plano de desenvolvimento entre o servidor e seus superiores. Isso revela a pactuação, estágio avançado no que se refere ao desenvolvimento de carreiras e posterior avaliação dos servidores e da instituição (SouZA, 2004).

No que se referem à educação, experiências na gestão por competências têm sido pautadas nas políticas públicas, em especial no ensino tecnológico. Todavia, parecem mais visíveis e consequentemente mais aceitas na regulação do ensino superior, a exemplo dos processos de avaliação de cursos, em que os descritores 
de competências estão presentes na concepção didático-pedagógica, no corpo docente e na própria infraestrutura das instituições avaliadas. De um modo geral, grande parte dos cursos superiores das instituições de ensino superior usa esses instrumentos como referencial de competências.

Zamberlan (2006), por sua vez, elucida as competências dos coordenadores de cursos de uma universidade federal brasileira, para fins de qualidade nos programas de ensino, pesquisa e extensão. $\mathrm{O}$ autor constata que esses gestores estão orientados para as competências. No entanto, observa diferenças em relação às variáveis que tratam da habilidade comportamental de trabalhar em equipe e saber se relacionar, $\mathrm{da}$ atitude profissional com a intenção de algo realizar, e da sinergia entre conhecimento, habilidades e atitudes. A falta de atitude e de capacidade de trabalho em equipe, associada à dificuldade de relacionamento, aparece com relativa influência negativa no desenvolvimento de competências organizacionais nessa pesquisa.

Já os estudos de André e Ciampone (2008) mostram uma limitação. As autoras realizaram pesquisa junto a dezenove gestores de uma Supervisão Técnica de Área da Secretaria Municipal de Saúde de São Paulo, que revela que a percepção dos gestores em relação às competências para gerir uma unidade básica de saúde baseiase em uma visão simplista, que influencia diretamente o modo de operacionalização das estratégias, e na dinâmica das equipes, dificultando a implementação de propostas mais eficazes. $\mathrm{O}$ fato de haver no mesmo local de trabalho funcionários que exercem funções semelhantes e que recebem salários distintos é apontado como uma dificuldade na gestão de recursos humanos e parece que limita o avanço na gestão por competências. Também constataram que as competências desses profissionais não favorecem a implementação dos novos modelos assistenciais e gerenciais, que incluem estratégias que lhes são inerentes, tendo em vista que não se percebem e nem são reconhecidos pelo seu grupo de referência como liderança. Isto infere limitação em quesitos atitudinais, como negociação, gerenciamento de conflitos e o fomento de um ambiente produtivo de trabalho.

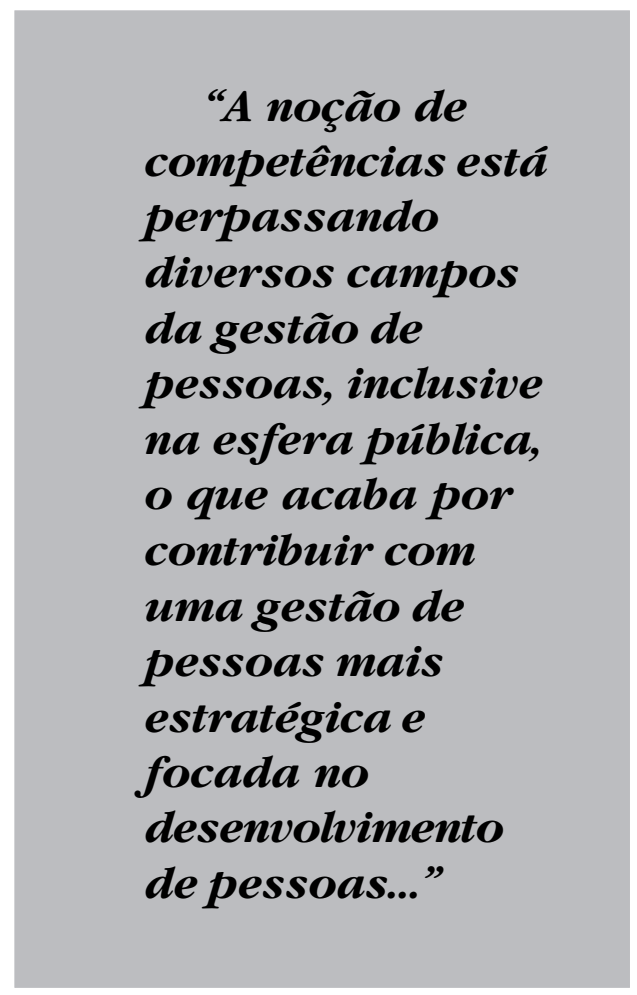

Percebe-se que o despreparo dos gestores influencia diretamente o modo de operacionalização das estratégias e a dinâmica das equipes envolvidas nos serviços, podendo levar à ineficácia e ineficiência dos processos.

A noção de competências está perpassando diversos campos da gestão de pessoas, inclusive na esfera pública, o que 
acaba por contribuir com uma gestão de pessoas mais estratégica e focada no desenvolvimento de pessoas que tenham relação com aquilo que a organização preza como eficiente e, consequentemente, com maior efetividade. Sabe-se que o desafio de implementar essas ações ainda é grande, principalmente quando se fala em atrelar pessoas à estratégia da organização. Mas o caminho revela ações em curso.

\section{Comentários finais}

Embora existam algumas práticas voltadas à atuação estratégica de organizações no que tange à aplicação da noção de competências, o caminho a percorrer ainda é longo. Um dos motivos que levam a isso está relacionado ao fato de se considerar as vantagens e limitações na aplicação da abordagem por competências, quando se trata do savoir-faire: as chamadas manhas do ofício. Essas implicam significativa habilidade em oposição aos saberes dos bacharéis, por exemplo, ou de cargos de hierarquia superior, na medida em que surgem em complementaridade às performances da técnica e, consequentemente, se tornam visíveis.

Outro elemento relevante refere-se à experiência do profissional, ilustrada pelo trabalhador que conhece tão bem seu meio de trabalho a ponto de poder antecipar suas reações. Tal domínio parece ser impossível de automatizar e indispensável ao bom funcionamento das instalações automatizadas. Mas por outro lado, a limitação pode estar nas disputas de poder diante do domínio do savoir-faire, o que pode comprometer as relações interpessoais e intergrupais, assim como incidir diretamente no desempenho organizacional desejado. O destaque é dado para concepções de competências coletivas e elementos de articulação entre competências individuais e organizacionais.

Por isso, parece conveniente atentar para os trabalhadores com competências tácitas, de modo que não se sintam ameaçados diante da implementação de novas estratégias na gestão de pessoas e do próprio negócio, mas sim estimulados a contribuir com os objetivos organizacionais e, em especial, com a própria elaboração e descrição das competências funcionais.

Pode-se dizer que o sucesso no desenvolvimento da gestão por competências também está em reconhecer que, por ser uma abordagem com foco nas pessoas, se trata de um processo evolucionário com eventos planejados e espontâneos que visam transformar comportamentos e atitudes, o que leva tempo e exige paciência ao longo das ações organizacionais do dia a dia.

Então, há de se considerar que obstáculos podem comprometer a gestão por competências. No individual, o que inibe o desenvolvimento de competências são fatores de ordem psicológica, desde as percepções de gerentes e colaboradores sobre suas necessidades e habilidades para aprender, as emoções, sentimentos e reações diante dos desafios e resolução de problemas, a fatores mais de fundo como valores e crenças. No organizacional, a cultura e o próprio clima podem se mostrar como inibidores do desenvolvimento de competências, assim como a instabilidade de mercado e a competição diante da posição econômica desejada, que na maior parte dos casos privilegia os resultados, mais que os processos de desenvolvimento de gestão de pessoas.

(Artigo recebido em junho de 2011. Versão final em setembro de 2011). 


\section{Referências bibliográficas:}

André, Adriana Maria; Ciampone, Maria Helena Trench. Competências para a gestão de Unidades Básicas de Saúde: percepção do gestor. In: Revista da Escola de Enfermagem da USP, 2007; 41(Esp): 835-40. Disponível: www.ee.usp.br/reeusp.

BARNEY, J. B. Strategic factor markets: expatiation, lucky and business strategy. Management Science, v.32, n.10, p1231 - 1241, 2001.

Becker, G. V.; Lacombe, B. M. B. Gestão, Inovação e Competências: conciliando idéias no estudo dos empreendedores de incubadora da base tecnológica. In: RuAs, R. L.; Antonello, C. S.; Boff, L. H. (Org.). Os Novos Horizontes da Gestão: aprendizagem organizacional e competências. Porto Alegre: Bookman, 2005. p. 168-186.

Borges-Andrade, Jairo E. et al (Orgs.) Treinamento, desenvolvimento e educação em organiz̧ações e trabalho: fundamentos para a gestão de pessoas. Porto Alegre: Artmed. 2006.

BosquetTi, M. A. Gestão de pessoas, estratégia e performance organizaional: um estudo internacional de multicasos. 2009. Tese (Doutorado em Administração) - Faculdade de Economia, Administração e Contabilidade da Universidade de São Paulo, São Paulo.

BoyATzIs, R. E. The competent management. a model for effective performance. New York: Jonh Wiley, 1982.

Deluiz, Neise. A Globalização Econômica e os Desafios à Formação Profissional. In: Boletim Técnico do SENAC, Rio de Janeiro, v. 30, n. 3, p.72-79, set./dez. de 2004.

O modelo das competências profissionais no mundo do trabalho e na educação: implicações para o currículo. In: Boletim Técnico do SENAC, Rio de Janeiro, v. 27, n. 3, set/dez. de 2001.

Dutra, J. S. Gestão de pessoas com base em competências. In: Dutra, J. S. et al. (coord.). Gestão por Competências: um modelo avançado para o gerenciamento de pessoas. São Paulo: Gente, 2001.

. Competências: conceitos e instrumentos para a gestão de pessoas na empresa moderna. São Paulo: Atlas, 2004.

. Competências: Conceitos e Instrumentos para a Gestão de Pessoas na Empresa Moderna. São Paulo: Atlas, 2008.

Dutra, J. S. (Org.); Fleury, M. T. L. (Org.); Ruas, R. L. (Org.). Competências: Conceitos, Métodos e Experiências. São Paulo: Atlas, 2008.

Fisher, A. L.; Fleury, Maria Tereza Leme; Urban, T. P.. Cultura e Competência Organizacional. In: DutRA, J. S.; Fleury, M. T. L.; RuAs, R. L. (org.) Competências: conceitos, métodos e experiências. São Paulo: Atlas, 2008

Fleury, M. T. L.; Fleury, A. Alinhando estratégia e competências. Revista de Administração de Empresas, v. 44, n. 1, p. 44-57, 2004.

- Estratégias empresariais e formação de competências: um quebra-cabeça caleidoscópio da indústria brasileira. $3^{\mathrm{a}}$ Ed. São Paulo: Atlas, 2006.

.Gestão estratégica do conhecimento: integrando aprendizagem, conhecimento e competências. São Paulo: Atlas, 2008. 
Grimand, A. Des compétences individuelles aux compétences stratégiques. Un essai de modélisation des stratégies concurrentielles fondées sur les ressources humaines. In:

Harvey, D. Condição Pós-moderna. São Paulo, Loyola, 1996.

Hock, D. Nascimento da era caórdica. SP: Cultrix. Amaná-Key, 1999.

Lacombe, M. B. Avaliação e mensuração de resultados em gestão de pessoas e a relação com o desempenho organizacional: um estudo com as maiores empresas brasileiras. Relatório de pesquisa. Escola de Administração de Empresas de São Paulo, Fundação Getúlio Vargas. São Paulo, 2006.

Le Boterf, G. De la compétence. Paris: Les Editions d'Organization, 1995.

Marconi, Nelson. Políticas Integradas de Recursos Humanos para o Setor Público. In: Programa avançado em gestão pública contemporânea. EGAP/FUNDAP, 2004.

Mascarenhas, André Ofenhejm. Gestão estratégica de pessoas: evolução, teoria e crítica. São Paulo: Cencage Learning, 2008.

Mcclelland, D. C. Testing for competencies rather than for intelligence. American Psychologist, Washington, D. C., no 28, p. 1-4, 1973.

Mello, Simone Portella Teixeira de. Tecnólogo: competências e mercado de trabalho. Pelotas: UFPel, 2009.

Mertens, Leonard. Competencia laboral: sistemas, surgimiento y modelos. Montevideo: Cinterfor, 1996.

Miles, R.; SNOw, C. C. Organizational strategy, structure and process. Sanford, CA: University Press, 2003.

Penrose, E. The Theory of the Growth of the Firm. Oxford: Oxford University Press, 1959. PIREs, Alexandre Kalil et al. Gestão por competências em organizações de governo. Brasília: ENAP, 2005.

PORTER, M. E. Estratégia competitiva. Técnicas para análise de indústrias e da concorrência. $7^{\text {a }}$ ed. Rio de Janeiro. Campus, 1986.

Prahalad, C.K.; Hamel, G. A Competência Essencial da Corporação. In Ulrich, D. (Org.) Recursos Humanos Estratégicos. São Paulo: Futura, 2000.

Retour, Didier et al. Competências coletivas. no limiar da estratégia. Porto Alegre: Bookman, 2011.

Ropé, Françoise; TANGuY, Lucie. Saberes e competências: o uso de tais noções na escola e na empresa. Campinas, SP: Papirus, 1997.

Ruas, R. L.; Antonello, C. S.; Boff, L. H. Aprendizagem organizacional e competências. Porto Alegre: Bookman, 2005.

RumeLt, R. P. Towards a strategic theories of the firm. In: Fosso, N. J. Resources, firm and strategies: a reader an resourced-basead perspective. New York: Oxford University Press, 1984.

SouzA, Regina Luna Santos de. Gestão por competências no governo federal brasileiro: experiência recente e perspectivas. In: IX Congreso Internacional del CL AD sobre la Reforma del Estado y de la Administración Pública, Nov. 2004, Madrid, España. 
TARtuce, Gisela L. B. P. Algumas reflexões sobre a qualificação do trabalho a partir da sociologia francesa do pós-guerra. In: Educação \& Sociedade, Campinas, v. 25, n. 87, p. 353-382, maio/ago. 2004. Disponível em: http://www.cedes.unicamp.br

Teece, D. J.; Pisano, G.; Shuen, A. Dynamic Capabilities and Strategic Management. Strategic Management Journal, Sussex, UK, v. 18, n. 7, p. 509-533, aug. 1997.

Wernerfelt, B. A Resource-based View of the Firm. Strategic Management Journal, v. 5, p. 171-180, 1984.

ZAMBERLAN, C.O. Orientação para a aprendizagem, gestão por competências e comprometimento organizacional nas instituições de ensino superior. Dissertação de Mestrado, PGA, UFSM, RS, 2006.

Zarifian, P. A gestão da e pela competência. In: Seminário Internacional Educação Profissional, Trabalho e Competências, 1996, Rio de Janeiro. Anais... Rio de Janeiro: SENAI, 1998. p.15-24.

. Objetivo Competência: por uma nova lógica. São Paulo: Atlas, 2001. 


\section{Resumo-Resumen-Abstract}

\section{A noção de competência na gestão de pessoas: reflexões a partir de casos do setor público}

Francielle Molon da Silva e Simone Portella Teixeira de Mello

O presente ensaio traz à discussão a gestão por competências como atributo elementar para o desempenho organizacional, considerando o impacto que alterações sociais e econômicas têm no trabalho. O objetivo deste é contribuir para reflexões por parte de gestores, colaboradores e pesquisadores sobre a gestão por competências enquanto parte de uma gestão estratégica de pessoas, com uma visão mais abrangente. Para tanto, fez-se uma revisão bibliográfica que evidenciou a importância da gestão por competências no desempenho organizacional e na gestão estratégica de pessoas. O estudo aponta que o caminho ainda é vasto e impreciso nas empresas públicas pela complexidade cultural e política envolvida. O sucesso no desenvolvimento da gestão por competências (individual e organizacional) está em reconhecer que, por ser uma abordagem com foco nas pessoas, se trata de um processo evolucionário com eventos planejados e espontâneos que visam transformar comportamentos e atitudes, o que leva tempo e exige paciência ao longo das ações organizacionais do dia a dia.

Palavras chave: gestão pública; gestão de recursos humanos; competências.

\section{El concepto de competencia en la gestión de personas: reflexiones sobre casos del sector público \\ Francielle Molon da Silva y Simone Portella Teixeira de Mello}

Este ensayo discute acerca de la gestión de competencias como un atributo elemental para el desempeño de la organización, teniendo en cuenta el impacto de los cambios sociales y económicos en el trabajo. Su objetivo es contribuir a la reflexión sobre la gestión de competencias por los gerentes, empleados e investigadores, como parte de una gestión estratégica del personal, con una visión más amplia. Por lo tanto, se realizó una revisión de la literatura, que ha puesto en evidencia la importancia de la gestión de competencias en el desempeño organizacional y en la gestión estratégica del personal. El estudio señala que el camino todavía es amplio e impreciso en las empresas públicas, debido a la complexidad cultural y política en cuestión. Sin embargo, lo que inhibe el desarrollo de competencias individuales son los factores psicológicos, que van desde la percepción de los gerentes a las reacciones de los servidores frente a nuevos problemas. El desarrollo de la gestión por competencias (individual y organizacional) es reconocer la importancia de ser un enfoque centrado en la gente y un proceso evolutivo con eventos programados y espontáneos que tienen como objetivo cambiar los comportamientos y actitudes, lo cual lleva tiempo y paciencia para las acciones de la organización día a día.

Palabras clave: gestión pública; gestión de los recursos humanos; competencias

\section{The notion of competence in the human resources management: reflections about cases of the public sector}

Francielle Molon da Silva and Simone Portella Teixeira de Mello

This essay discusses about competencies-based management as an elemental attribute for an organizational performance, considering the social and economic changes impact on work. Its objective is to contribute to reflections by managers, laborers, and researchers on competencies management as part of strategic people management with a broader view. Therefore we conducted a literature review that has evidenced the importance of competencies-based management in the organizational performance and in strategic people management. The study points out that the path is still wide 
and imprecise in the public company, because of cultural and policy complexity involved. However, what inhibit the development of individual skills are the psychological factors, ranging from perception of managers to reactions of laborers face new problems. The development of competencies management (individual and organization) is to be recognized if the approaches are is going to be focusing on people and being an evolutionary process with planned and spontaneous events that aim to change behaviors and attitudes, which makes time and patience to organizational actions over day by day.

Keywords: public management; human resources management; competencies

Francielle Molon da Silva

Especialista em Gestão de Pessoas (Universidade Católica de Pelotas), Mestre em Recursos Humanos (Escola de Administração da Universidade Federal do Rio Grande do Sul) e atualmente é doutoranda em Recursos Humanos também pela Escola de Administração da Universidade Federal do Rio Grande do Sul.

Contato: franmolon@yahoo.com.br

Simone Portella Teixeira de Mello

Doutoranda em Educação pela Universidade Federal do Rio Grande do Sul. É professora do curso de Administração, Empresas e Comércio Exterior da Universidade Federal do Pampa (Unipampa/RS).

Contato: sptmello@gmail.com 


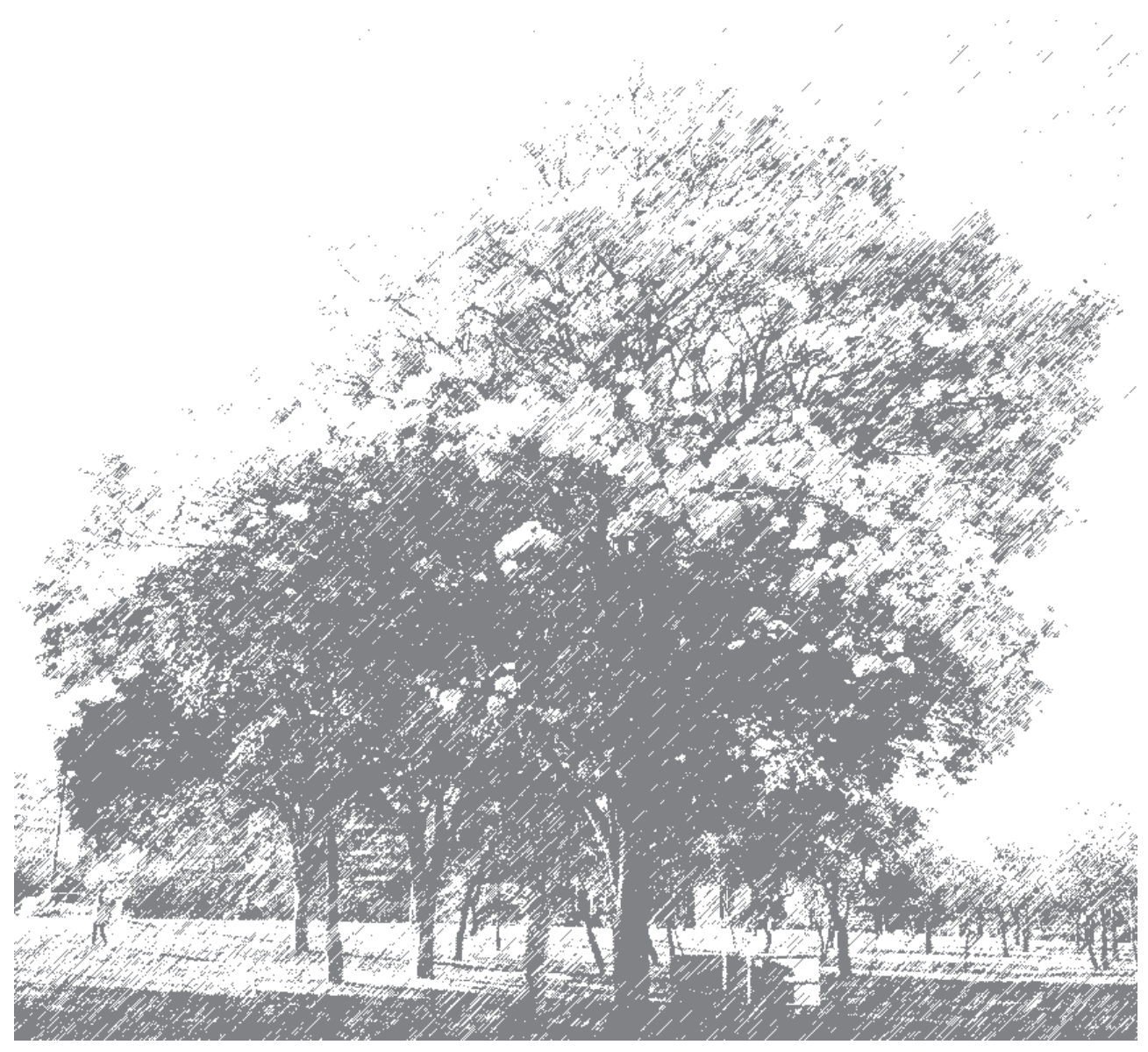

